\title{
Is leprosy blindness avoidable? \\ The effect of disease type, duration, and treatment on eye damage from leprosy in Uganda
}

\author{
Keith M Waddell, Paul R Saunderson
}

\begin{abstract}
Aims-The study was designed to measure the prevalence, range, and severity of eye involvement in leprosy patients; to relate this to disease type, duration, and treatment to identify risk factors; and to provide practical guidelines for programme managers and field staff on the prevention of blindness.

Methods-The visual outcome was assessed in a population based sample of patients in Kasese District, Uganda followed for up to two decades, and related to disease features and treatment. A total of 678 patients responded to an invitation out of 2715 registered since 1973.

Results-Low vision was present in $4 \cdot 4 \%$ of people and blindness in $1 \cdot 3 \%$, with $1.5 \%$ and $0.6 \%$ respectively being due to leprosy. Some $12 \cdot \mathbf{4} \%$ of patients had iritis, of whom $33 \%$ had visual loss in one or both eyes, $3 \cdot 7 \%$ of patients had lagophthalmos, and $11 \cdot 7 \%$ had lens opacity. For multibacillary (MB), as opposed to paucibacillary (PB) cases, the adjusted odds ratios were: for iritis $4.6(95 \%$ CI $2 \cdot 6-8 \cdot 2)$, for lagophthalmos $1.4(0 \cdot 6-3 \cdot 2)$, and for lens opacity $1 \cdot 7 \quad(1 \cdot 0-3 \cdot 0)$. Potentially sight threatening (PST) lesions were present in $16 \cdot 8 \%$ of patients $(95 \%$ CI $14 \cdot 0-19 \cdot 6)$.
\end{abstract}

Conclusion-Levels of eye involvement in this study are low compared with many surveys. Visual loss is uncommon and is more often caused by other diseases; in the present era of multidrug therapy (MDT) it is very unlikely to be caused by leprosy. It is more common with advancing age. PST lesions, especially iritis, may occur in both PB and MB cases, even if the diagnosis of leprosy is made early and MDT started immediately; they may occur also after completion of MDT. But eye complications need not proceed to loss of sight if treated promptly, and blindness can be avoided. Training of front line staff is therefore crucial.

(Br f Ophthalmol 1995; 79: 250-256)

PO Box 4008, Kampala, Uganda $\mathrm{K} M$ Waddell

ALERT, PO Box 165, Addis Ababa, Ethiopia P R Saunderson

Correspondence to: Dr K M Waddell.

Accepted for publication 16 November 1994 been reputed to be the systemic disease with the highest frequency of eye complication with marked risk of blindness in many surveys. ${ }^{23}$ But as Courtright has shown, ${ }^{3}$ all surveys have methodological flaws, preventing definition of incidence or prevalence, or of levels of disability or blindness. In summary the defects he specifies are unrepresentative samples, inadequate instruments and untrained examiners, and failure to analyse by clinical type, duration, or treatment. So true levels of damage are uncertain. In old patients living near leprosaria, blindness may be all too common, but this is biased and modern treatment should be markedly changing the picture.

Kasese District lies around the southern part of the Ruwenzori Mountains in Uganda, adjoining Zaire. It is inhabited mostly by the Bakonzo people (population in 1991 census 343601 ). The authors have been responsible for the leprosy programme there from 1973 (KW 1973-80; PS 1981-92; eye care KW 1965-94), based at Kagando Hospital. During this period this area has suffered from repeated civil strife and economic hardship. Thus patients' access to medical services (which were underdeveloped anyway) has been very disrupted. In 1990-1 the eyes of all past or present patients who could be located were examined. This was to upgrade their eye care and plan for its improvement, and also to try to satisfy Courtright's reservations. The patients were examined generally also as part of their ongoing care, and findings and past records were transferred to computer. These are analysed by disease type (the patient's position in the immunological spectrum), by disease duration, and by treatment to get an estimate of eye complications as unbiased as possible for a field situation. We hoped to document a fall in eye damage since the introduction of MDT, as now recommended by WHO, for all patients. ${ }^{4}$

\section{Materials and methods}

\section{PATIENTS}

Records exist for 2715 patients registered from 1973 till 1991. Many were already old cases, some from the $1950 \mathrm{~s}$ and $46 \%$ had started treatment before the end of 1973. All had full clinical examination and from 1973 were documented in detail on a standard form (Ministry of Health). Their ages are often estimates in this semiliterate community. Seventy three per cent had skin smears taken from four to six sites and repeated as often as necessary. A study checked the reliability of these. ${ }^{5} \mathrm{~A}$ few had biopsy but lepromin testing was not done. All were seen or checked by senior staff initially and repeatedly for as many years of follow up as needed. The position of each in the Ridley-Jopling (RJ) classification ${ }^{6}$ 
was recorded and revised if needed from later findings. The classification has a spectrum of five groups from high to low resistance - TT, $\mathrm{BT}, \mathrm{BB}, \mathrm{BL}$, and $\mathrm{LL}$. In earlier years visual acuity was not recorded and ocular examination was by naked eye or loupe only. All patients lived at home and attended for monthly supplies of medication at their nearest health post. Hospital admission (most to Kagando) was for complications only.

\section{TREATMENT}

Originally from the 1950 s this was dapsone monotherapy for prolonged periods. When dapsone resistance threatened, additional drugs were used, starting in 1974 with clofazimine and in 1977 with rifampicin. These were at first used for very bacilliferous patients not improving on monotherapy, or for reactions. But use was increased so that by 1980 most with positive smears were getting two or three drugs in varying regimens. The WHO pattern of MDT was introduced through that decade and by 1989 it was universal. Treatment of eye complications included

Table 1 Sample characteristics

\begin{tabular}{lll}
\hline & $\begin{array}{l}\text { Total } \\
\text { (2715 patients) }\end{array}$ & $\begin{array}{l}\text { Sample } \\
\text { (678 patients; 25\%) }\end{array}$ \\
\hline Sex M/F & $56 / 44 \%$ & $60 / 40 \%$ \\
Multibacillary & $30 \%$ & $45 \%$ \\
Date of start & & \\
$\quad$ Before 1974 & $46 \%$ & $32 \%$ \\
1974 to 1979 & $18 \%$ & $10 \%$ \\
1980 to 1985 & $20 \%$ & $17 \%$ \\
1986 to 1991 & $16 \%$ & $41 \%$ \\
Rifampicin used & $46 \%$ & $88 \%$ \\
Attendance - good & & \\
(>75\%) & $67 \%$ & $88 \%$ \\
Present age & & \\
5 to 29 years & $28 \%$ & $25 \%$ \\
30 to 49 years & $37 \%$ & $43 \%$ \\
50 to 80 years & $18 \%$ & $32 \%$ \\
Unrecorded & $17 \%$ & $0 \%$
\end{tabular}

Table 2 Best visual acuity in 1356 eyes of 678 patients, according to age and WHO classification (eyes with decreased visual acuity (VA) due to leprosy)

\begin{tabular}{|c|c|c|c|c|c|c|c|}
\hline \multirow[b]{3}{*}{$V A$} & \multirow[b]{3}{*}{ Total } & \multicolumn{6}{|l|}{ Best VA } \\
\hline & & \multicolumn{2}{|c|}{ Normal 6/5-6/18 } & \multicolumn{2}{|c|}{ Low vision $6 / 24-3 / 60$} & \multicolumn{2}{|c|}{ Blind $2 / 60$ or less } \\
\hline & & Number & $\%$ & Number & $\%$ & Number & $\%$ \\
\hline $\begin{array}{l}\text { Age } 5-29 \text { years } \\
\text { MB cases } \\
\text { PB cases } \\
\text { Age } 30-49 \text { years }\end{array}$ & $\begin{array}{l}128 \\
208\end{array}$ & $\begin{array}{l}124 \\
205\end{array}$ & $\begin{array}{l}97 \\
99 \cdot 6\end{array}$ & $\begin{array}{l}2(2) \\
1(0)\end{array}$ & $\begin{array}{l}1.5(1.5) \\
0.5(-)\end{array}$ & $\begin{array}{l}2(1) \\
2(0)\end{array}$ & $\begin{array}{l}1.5(0.75) \\
1.0(-)\end{array}$ \\
\hline $\begin{array}{l}\text { MB cases } \\
\text { PB cases } \\
\text { Age } 50-80 \text { years }\end{array}$ & $\begin{array}{l}252 \\
346\end{array}$ & $\begin{array}{l}235 \\
337\end{array}$ & $\begin{array}{l}93 \cdot 3 \\
97 \cdot 4\end{array}$ & $\begin{array}{l}5(3) \\
5(0)\end{array}$ & $\begin{array}{l}2.0(1 \cdot 2) \\
1.4(-)\end{array}$ & $\begin{array}{r}12(5) \\
4(0)\end{array}$ & $\begin{array}{l}4 \cdot 7(2) \\
1 \cdot 2(-)\end{array}$ \\
\hline $\begin{array}{l}\text { MB cases } \\
\text { PB cases } \\
\text { All groups }\end{array}$ & $\begin{array}{r}226 \\
196 \\
1356\end{array}$ & $\begin{array}{r}165 \\
172 \\
1238\end{array}$ & $\begin{array}{l}73 \cdot 0 \\
87 \cdot 8 \\
91 \cdot 3\end{array}$ & $\begin{array}{l}42(14) \\
13(2) \\
68(21)\end{array}$ & $\begin{array}{c}18 \cdot 6(6 \cdot 2) \\
6 \cdot 6(1) \\
5 \cdot 0(1 \cdot 6)\end{array}$ & $\begin{array}{l}19(11) \\
11(3) \\
50(20)\end{array}$ & $\begin{array}{l}8.4(4.9) \\
5 \cdot 6(1.5) \\
3.7(1.5)\end{array}$ \\
\hline
\end{tabular}

$\mathrm{MB}=$ multibacillary; $\mathrm{PB}=$ paucibacillary .

Table 3 Reduced visual acuity (VA) among 678 patients (patients with decreased VA due to leprosy)

\begin{tabular}{|c|c|c|c|}
\hline & $V A$ in better eye & Number & $\%$ \\
\hline Visual impairment & $(6 / 24-6 / 60)$ & $24(5)$ & $3.5(0.7)$ (upper $95 \%$ CI: $4.9 \%(1.3 \%)$ ) \\
\hline $\begin{array}{l}\text { impairment } \\
\text { Blind } \\
\text { Total }\end{array}$ & $\begin{array}{l}(5 / 60-3 / 60) \\
(2 / 60 \text { or less) }\end{array}$ & $\begin{array}{c}6(5) \\
9(4) \\
39(14)\end{array}$ & $\begin{array}{l}0.9(0 \cdot 7) \text { (upper } 95 \% \text { CI: } 1 \cdot 6 \%(1 \cdot 3 \%) \text { ) } \\
1.3(0 \cdot 6) \text { (upper } 95 \% \text { CI: } 2 \cdot 1 \%(1.2 \%) \\
5.7(2 \cdot 1) \text { (upper } 95 \% \text { CI: } 7 \cdot 4 \%(3.2 \%) \text { ) }\end{array}$ \\
\hline
\end{tabular}

topical atropine and steroids for iritis, and systemic steroids for recent paralysis, including facial paralysis. If the patient did not attend, a complication would not be tackled early, or be untreated.

\section{EYE EXAMINATION}

By word of mouth (patients have no postal addresses) all past and present leprosy patients were invited to attend their local health post for an eye examination. In each of 3 months (May 1990, December 1990, Nov/Dec 1991) each post was visited. A visual acuity and detailed eye examination was done (by $\mathrm{KW}$ ). The protocol used was expanded from that of Courtright and Johnson. ${ }^{7}$ Biomicroscopy (Zeiss SL10) and direct ophthalmoscopy were routine. Refraction, tonometry (Perkins applanation), and indirect ophthalmoscopy were not routine but done as clinically indicated. Lens opacities were graded according to Mehra et al, ${ }^{8}$ with grade $2 \mathrm{~A}$ (at least $1 \mathrm{~mm}^{2}$ in an undilated pupil obscured by opacity) being taken as the minimum for analysis. Treatment was arranged for any eye pathology found. Patients were judged to have had iritis if they had one or more of these features: keratic precipitates, aqueous cells and flare, posterior synechiae, or organised exudate at the pupil margin. Also scored were past documented attacks of iritis even if no residual signs were found. Lagophthalmos was recorded if any gap occurred on light or strong lid closure, or a past documented episode even if now recovered. Any corneal pathology was assessed as to whether it was from exposure or not. Miosis was judged to be present if the pupil was smaller than a $2 \mathrm{~mm}$ template indoors, without synechiae. These lesions, plus lens opacities in their presence (not if isolated), were assigned to leprosy as a cause, and separated from all other pathologies in the analysis.

On the same occasion a general examination was done (by PS) and smears repeated if necessary. A total of 690 patients were examined at one or more of the visits; 12 were excluded from the analysis as they had no records leaving 678 for analysis. All but one of the exclusions dated from before 1973, and two had eye pathology (both aphakic). The ages of patients examined range from 5-80 years.

\section{ANALYSIS OF DATA}

The details of eye findings were recorded in a standard manner and transferred to a computer form. Details of general disease, and of past history and treatment from the records of all 2715 patients were similarly computerised. All records were also scanned to find any eye problems recorded. Cases towards the lepromatous side (BB, $B L$, and $L L)$ were classed as $M B$, and those towards the tuberculoid side (BT and TT) as PB. The data were analysed and statistical procedures done using the program EPI INFO 5 (CDC, Atlanta and WHO, Geneva). Multiple logistic regression modelling was performed using EGRET software. 
Table 4 Iritis - presence or absence in 678 patients, according to age and Rf classification

\begin{tabular}{|c|c|c|c|c|c|c|c|c|c|c|c|c|}
\hline \multirow[b]{2}{*}{ Classification } & \multicolumn{4}{|c|}{$\begin{array}{l}\text { Age group 5-29 (years) } \\
\text { Iritis }\end{array}$} & \multicolumn{4}{|c|}{$\begin{array}{l}\text { Age group 30-49 (years) } \\
\text { Iritis }\end{array}$} & \multicolumn{4}{|c|}{$\begin{array}{l}\text { Age group 50-80 years } \\
\text { Iritis }\end{array}$} \\
\hline & Present & Absent & Total & $\%$ & Present & Absent & Total & $\%$ & Present & Absent & Total & $\%$ \\
\hline $\begin{array}{l}\text { LL } \\
\text { BL } \\
\text { BB } \\
\text { BT } \\
\text { TT } \\
\text { Totals }\end{array}$ & $\begin{array}{l}3 \\
5 \\
- \\
- \\
\overline{8}\end{array}$ & $\begin{array}{r}12 \\
42 \\
4 \\
75 \\
27\end{array}$ & $\begin{array}{r}15 \\
47 \\
4 \\
75 \\
27 \\
168\end{array}$ & $\begin{array}{l}20 \\
10 \cdot 6 \\
- \\
- \\
\overline{4} \cdot 8\end{array}$ & $\begin{array}{r}11 \\
17 \\
1 \\
6 \\
- \\
35\end{array}$ & $\begin{array}{r}29 \\
70 \\
4 \\
123 \\
38\end{array}$ & $\begin{array}{r}40 \\
87 \\
5 \\
129 \\
38 \\
299\end{array}$ & $\begin{array}{r}27 \cdot 5 \\
19 \cdot 5 \\
20 \cdot 0 \\
4 \cdot 7 \\
\overline{11} \cdot 7\end{array}$ & $\begin{array}{r}15 \\
15 \\
1 \\
9 \\
1 \\
41\end{array}$ & $\begin{array}{r}28 \\
52 \\
5 \\
57 \\
28\end{array}$ & $\begin{array}{r}43 \\
67 \\
6 \\
66 \\
29 \\
211\end{array}$ & $\begin{array}{r}34.9 \\
22 \cdot 4 \\
16 \cdot 7 \\
13 \cdot 6 \\
3.4 \\
19 \cdot 4\end{array}$ \\
\hline
\end{tabular}

$\mathrm{LL}=$ lepromatous leprosy; $\mathrm{BL}=$ borderline lepromatous; $\mathrm{BB}=$ mid-borderline; $\mathrm{BT}=$ borderline tuberculoid; $\mathrm{TT}=$ tuberculoid leprosy.

\section{Results}

SAMPLE CHARACTERISTICS

Table 1 shows differences between all patients and the sample examined.

\section{BEST VISUAL ACUITY}

Table 2 shows the number of eyes in each category of best visual acuity (that is after refraction or treatment) against disease type (MB or $\mathrm{PB}$ ) and age. In brackets are the numbers with visual loss from causes specific to leprosy.

\section{REDUCED VISUAL ACUITY}

Table 3 shows the number of patients with reduced visual acuity from all causes, the better eye being recorded. In brackets are the numbers caused by leprosy, the primary cause of this in each case being iris damage, with or without lens opacity. Six of these had one or more limb with grade 2 disability (current WHO grading), but in only one were all four limbs damaged. Thirteen additional patients had visual loss in one eye due to leprosy, making 41 eyes in 27 patients affected altogether. Thirteen of the bilateral cases were lepromatous (LL) or borderline lepromatous (BL) as were 12 of the unilateral ones. Twelve of the 14 bilateral cases had started treatment before 1973, as had 12 of the 13 unilateral cases. Reasons why the remaining three who started in the modern era had lost vision are discussed in the case presentations (cases 3-5).

IRITIS

Table 4 shows number of patients with present or past iritis by $\mathbf{R J}$ classification, stratified by age group. Twenty eight of the $84(33 \%)$ had vision of $6 / 24$ or worse in one or both eyes.

Table 5 Risk factors associated with iritis in 678 patients

\begin{tabular}{lll}
\hline Risk factor & Adjusted odds ratio & 95\% Confidence intervals \\
\hline Age 5-29 years & 1 & \\
Age 30-49 years & $1 \cdot 9$ & $0 \cdot 8-4 \cdot 4$ \\
Age 50-80 years & $2 \cdot 6$ & $1 \cdot 1-6 \cdot 1$ \\
Duration of disease $<18$ years & 1 & $0.98-3 \cdot 2$ \\
Duration >18 years & $1 \cdot 8$ & \\
Classification: PB & 1 & $2 \cdot 6-8 \cdot 2$ \\
Classification: MB & $1 \cdot 6$ & $0 \cdot 88-3.9$ \\
Rifampicin within 1 year of diagnosis & $1 \cdot 8$ & Rifampicin delayed or never given
\end{tabular}

^Determined by multiple logistic regression modelling of all listed factors.
Four patients who had all started rifampicin 2 to 11 years before still had active iritis. No case of pupil block glaucoma from synechiae nor angle closure from atropinisation was seen. No iris pearls were seen.

Table 5 shows the results of a multiple logistic regression analysis for various risk factors for iritis. Multibacillarity is the strongest risk followed by increasing age. Duration of disease over 18 years and a delay in starting rifampicin for at least 1 year failed to reach significance. In addition iritis was analysed against the highest bacterial index (BI) at any site in the first three smears of all active MB patients. This showed that there was no significant difference between the mean of the highest BIs in those with iritis $(4 \cdot 3)$ and in those without $(4 \cdot 0 ; p=0 \cdot 15$, Student's $t$ test).

\section{LAGOPHTHALMOS}

Twenty five patients (3.7\%) had lagophthalmos in one or both eyes, nine of these $(1.3 \%)$ having corneal damage. For MB as opposed to PB patients, the odds ratio for lagophthalmos is $1 \cdot 4(95 \%$ CI $0 \cdot 6-3 \cdot 2)$. Multiple logistic regression modelling confirmed the lack of any significant relation with classification, also with age, duration of disease, or timing of MDT. Fourteen of the 25 were post 1973 cases, evenly spread throughout the period. Three had corneal damage, but it was slight in all. None of these 14 had diminished corneal sensation, or decreased visual acuity; six no longer have lagophthalmos.

\section{LENS OPACITY}

Table 6 shows the number of patients with lens opacity as defined above, plus aphakia, by RJ classification, stratified by age.

Table 7 shows the results of a multiple logistic regression analysis for lens opacity. Age is by far the most important risk factor, but iritis also makes a contribution. Multibacillarity on its own just fails to reach significance.

\section{CORNEAL HYPAESTHESIA}

Thirteen eyes of 10 patients had diminished sensation to cotton wool touch, and eight of these eyes had reduced vision. All were LL or BL except one TT patient with probable past herpetic keratitis. One of these patients also had bilateral lagophthalmos and one unilateral, 
Table 6 Lens opacity - presence or absence in 678 patients, according to age and Rf classification

\begin{tabular}{|c|c|c|c|c|c|c|c|c|c|c|c|c|}
\hline \multirow[b]{2}{*}{ Classification } & \multicolumn{4}{|c|}{$\begin{array}{l}\text { Age group 5-29 (years) } \\
\text { Opacity }\end{array}$} & \multicolumn{4}{|c|}{$\begin{array}{l}\text { Age group } 30-49 \text { (years) } \\
\text { Opacity }\end{array}$} & \multicolumn{4}{|c|}{$\begin{array}{l}\text { Age group } 50-80 \text { years } \\
\text { Opacity }\end{array}$} \\
\hline & Present & Absent & Total & $\%$ & Present & Absent & Total & $\%$ & Present & Absent & Total & $\%$ \\
\hline $\begin{array}{l}\text { LI } \\
\text { BL } \\
\text { BB } \\
\text { BT } \\
\text { TT } \\
\text { Totals }\end{array}$ & $\begin{array}{l}3 \\
\overline{1} \\
\frac{1}{4}\end{array}$ & $\begin{array}{r}12 \\
47 \\
4 \\
74 \\
27\end{array}$ & $\begin{array}{r}15 \\
47 \\
4 \\
75 \\
27 \\
168\end{array}$ & $\begin{array}{l}20.0 \\
- \\
\overline{1} \cdot 3 \\
\overline{2.4}\end{array}$ & $\begin{array}{r}7 \\
6 \\
\overline{4} \\
\overline{17}\end{array}$ & $\begin{array}{r}33 \\
81 \\
5 \\
125 \\
38\end{array}$ & $\begin{array}{r}40 \\
87 \\
5 \\
129 \\
38 \\
299\end{array}$ & $\begin{array}{c}17.5 \\
6.9 \\
- \\
3.1 \\
\overline{5} .7\end{array}$ & $\begin{array}{r}13 \\
21 \\
1 \\
14 \\
9 \\
58\end{array}$ & $\begin{array}{r}30 \\
46 \\
5 \\
52 \\
20\end{array}$ & $\begin{array}{r}43 \\
67 \\
6 \\
66 \\
29 \\
211\end{array}$ & $\begin{array}{l}30.2 \\
31.3 \\
16.7 \\
21.2 \\
31.0 \\
27.5\end{array}$ \\
\hline
\end{tabular}

and these three eyes were the only ones that had lost vision from exposure. Enlarged corneal nerves were not seen on biomicroscopy in any case.

\section{MIOSIS}

Simple miosis was present in 13 eyes of 10 patients, of whom nine were $\mathrm{MB}$ and seven had visual loss in the affected eyes.

Potentially sight threatening (PST) lesions from leprosy only - that is, iritis, lagophthalmos, miosis, or hypaesthesia, were present alone or in combination in 114 patients with 172 out of 1356 eyes affected $(16.8 \%$ of patients, $95 \%$ CI $14 \cdot 0-19 \cdot 6 \% ; 12 \cdot 6 \%$ of eyes, 95\% CI 11.6-13.7\%).

\section{Case reports}

Five short case reports illustrate the range of cases seen. Case 3 with unilateral loss, and cases 4 and 5 with bilateral loss, are the only five eyes to have lost vision in the modern era.

\section{CASE 1}

NM male; born 1962. This man presented in 1980 aged 18 requesting a leprosy examination. Clinically, there were no signs but skin smears were done. These were positive the BI being 3.6 (highest 5) with solid organisms, meaning active $\mathrm{MB}$ disease despite the lack of visible signs. His eyes were normal. Treatment was started at once with 7 days of rifampicin and continued with dapsone and clofazimine until discharge in 1989. His eyes have remained normal and he represents the ideal and usual outcome at the present time.

CASE 2

YS male; born 1930. This BL patient started dapsone monotherapy in 1965, and when first seen in 1973 had damage to all four limbs

Table 7 Risk factors associated with lens opacity in 678 patients

\begin{tabular}{|c|c|c|}
\hline Risk factor & Adjusted odds ratio ${ }^{\star}$ & $95 \%$ Confidence intervals \\
\hline $\begin{array}{l}\text { Age } 5-29 \text { years } \\
\text { Age } 30-49 \text { years } \\
\text { Age } 50-80 \text { years } \\
\text { Classification: PB } \\
\text { Classification: MB } \\
\text { No signs of iritis } \\
\text { Signs of previous/active iritis }\end{array}$ & $\begin{array}{c}1 \\
2 \cdot 2 \\
12 \cdot 6 \\
1 \\
1 \cdot 7 \\
1 \\
3 \cdot 0\end{array}$ & $\begin{array}{l}0 \cdot 71-6 \cdot 6 \\
4 \cdot 4-35 \cdot 9 \\
1 \cdot 0-3 \cdot 0 \\
1 \cdot 6-5 \cdot 5\end{array}$ \\
\hline
\end{tabular}

^Determined by multiple logistic regression modelling of all listed factors. and an active severe bilateral iritis. This was treated topically at that time. In 1978 dapsone resistance was suspected and MDT was started. He now has VA $6 / 6$ in each eye and the only abnormal signs are few tiny synechiae. $\mathrm{He}$ illustrates that even with eye involvement and suboptimal treatment of his leprosy, visual loss can be averted.

CASE 3

SK male; born 1951. This man presented in 1976 with active lepromatous disease and BI 2.5 (highest 5). He immediately defaulted from care and reappeared in 1989 with BI 5·1 and gross damage to all limbs. His VA was $6 / 12$ right and hand movements left. He had bilateral leprous keratitis, and in the left eye lens opacity, iris atrophy, and a limbal staphyloma. His infection has since been eradicated with MDT but the damage resulting from long default is irreversible.

\section{CASE 4}

KD female; born 1930. This woman presented in 1991 claiming to be a new case, but with damage already to both feet. Her BI was 1.0 (highest 2). Her VA was $5 / 60$ right and $2 / 60$ left. She had bilateral inactive iritis with synechiae plus lens opacities. Pressures were normal at $17 \mathrm{~mm} \mathrm{Hg}$ in both eyes. She has completed MDT and her cataracts have been extracted, so VA has improved with spectacles. Delay in presentation could be largely responsible for her eye damage.

\section{CASE 5}

KV male; born 1961. This man presented in 1989 with lepromatous disease (BI $4 \cdot 5$, highest 5) and at first, normal eyes. He was started at once on MDT. Within 6 months he had developed a severe bilateral iridocyclitis which did not remit on intensive topical atropine and dexamethasone. So a full dose of clofazimine (300 mg daily) was added for its anti-inflammatory effect and a tapering dose of prednisolone also. At present MDT is completed and he is on topical dexamethasone and atropine. $\mathrm{He}$ still has an active iridocyclitis with flare and cells, scleral thinning over the ciliary body, and early posterior subcapsular lens opacities, but no synechiae and normal pressures. His VA is $6 / 36$ in each eye. He illustrates how severe eye complications can still occur even with prompt MDT, but hopefully when it settles good vision can be restored. 


\section{Discussion}

SAMPLE BIAS

The aim was to have figures that were population based, but after so many years this could not be fully achieved. Also hopes of having longitudinal data to calculate incidences were not realised, as many episodes were not seen at onset. Twenty five per cent of all registered cases were seen or $31.5 \%$ of those starting treatment after 1973. So the question arises as to how representative the 678 examined patients are of the whole 2715 . Table 1 shows the former were weighted as expected towards more recent cases and use of MDT, which would tend to bias towards less damaged eyes. On the other hand patients with problems would be expected to attend (though blindness does impede travel) but the numerous undamaged ones discharged long ago would not. This would give a bias towards raised figures. The failure to find the rest is the result of several causes. Many have died (about $10 \%$ are recorded dead but this figure is incomplete), and death may be hastened by blindness, which might remove more serious cases. Many have migrated to the ethnically similar area in Zaire while others may not have received the invitation or declined it. With these many influences, the overall direction of bias is uncertain.

So in case damaged cases had been missed, these were looked for in other ways. Scanning all the notes revealed that few of the missing patients had eye lesions recorded. Of those starting treatment before April 1973, only 11 had marked eye damage from leprosy. Of 18 cases starting after that date with eye pathology recorded, but not seen for examination, none suggested visual loss from leprosy. Also the field workers who know the patients personally could find no others with eye damage. As of mid 1994, no further cases have been located by the ongoing programme, so the overall proportion with eye damage is unlikely to be very different, and the true prevalence may be even lower than estimated, if the unexamined eyes are mostly normal. While this sample is not truly representative, it is more so than in other surveys which have not attempted to look at the whole population over a prolonged period.

\section{FREOUENCY OF EYE DAMAGE}

When compared with many other surveys 239 the numbers with visual loss and eye pathology from leprosy itself are low, though the overall figure for PST lesions was $16 \cdot 8 \%$ of patients. Particularly high figures are often reported from India even when limited to PST lesions only. ${ }^{10}$ But figures for sub-Saharan Africa ${ }^{11} 12$ are more in line with the present survey. As most damaged eyes come from $\mathrm{MB}$ cases, the proportion of these will affect the overall figures, and it is often higher in India than Africa (though it was $45 \%$ in this sample). Part of the discrepancy may be a racial difference and so the continents are not directly comparable. Also as age is strongly related to visual loss, differing age structures will influence figures. But it is also likely that high figures arise when the sample studied includes many advanced cases treated long ago without modern drugs, and this probably accounts for much of the discrepancy. The present figures should be more realistic owing to the population base of the study.

Table 2 shows that the majority of cases of decreased visual acuity are in fact from causes not specific to leprosy. Lens opacity, presumed coincidental, is the commonest cause of visual loss. Other coincidental causes were corneal opacity (not from exposure), glaucoma, trauma, maculopathy, and amblyopia. However, visual loss is the same handicap to the patient whatever the cause and workers should have a broad knowledge of eye disease. Trachoma and onchocerciasis both occur in the area, but rarely damage sight and were not found in these patients.

\section{IRITIS}

Iritis (or more correctly iridocyclitis) is the main complication. As is well known, the risk in $\mathrm{MB}$ compared with PB patients is high (odds ratio 4.6). This reflects the underlying cause being invasion of the anterior uvea by Mycobacterium leprae in bacilliferous cases. Probably some attacks of iritis occur with reactions (Jopling type 2 ), but only a minority. ${ }^{13}$ This link was not documented here, as many cases were not seen until after the episode. Contrary to expectation several cases were found in PB patients (16 out of $364,4.4 \%$ ). Though the background rate for comparison is unknown, these seem too many to be coincidental (some are, as with one case having mainly posterior uveitis). A weak point in classification without biopsy is those cases with negative smears and classified as BT, but which may be about to downgrade to BL with multiplying bacilli. These may account for some 'paucibacillary' cases having iritis. But inspection of the records shows many are truly BT with few and stable lesions, and so iritis does seem to occur above background levels in this form.

Iritis need not cause damage if treated early, so it would be useful to be able to predict cases at high risk. As has been seen MB disease is a strong risk. Time between onset of leprosy and treatment might be another but is unmeasurable in this community. Some other possibilities were considered. The highest BI at any point proved to be not correlated. Surprisingly too there was no significant increase in the risk of developing iritis if rifampicin was delayed beyond a year after diagnosis. It seems then that the improved prognosis in recent years is due to the improved overall management and earlier presentation, and not to MDT alone. So in practice all cases (though especially MB) must be watched to detect complications. The four cases with active iritis long after starting MDT show how prolonged this can be, and so access to eye care must continue after MDT finishes.

Other reports ${ }^{1415}$ emphasise the common occurrence of a chronic low grade 'iritis' with minimal symptoms and ending with atrophy and miosis. This is believed to be due to a slow 
neuropathic degeneration rather than an iritis. In this survey simple miosis occurred in only 13 patients (but six lost vision) so it is not frequent, and iritis here implies a more florid process.

LAGOPHTHALMOS AND CORNEAL HYPAESTHESIA For lagophthalmos the risk is evenly spread across the spectrum with odds ratio near unity. This reflects the underlying cause being mostly a reacting facial patch involving the facial nerve (Jopling type 1 reaction), which can occur in all but fully polar cases. This link was not documented here, but is known from other studies. ${ }^{16}$ Corneal hypaesthesia occurs from trigeminal nerve damage. Karacorlu et $a l^{17}$ have reported its presence and increased severity in longstanding MB disease. They used an aesthesiometer under experimental conditions, but with a wisp of cotton wool it is difficult to interpret. In the presence of lagophthalmos it is an extra warning of danger from exposure damage, but otherwise it contributed little to care in this study. This is in contrast with present opinion (Workshop on the eye, 14th International Leprosy Congress 1993), and there may be geographical differences.

\section{LENS OPACITY}

The role of leprosy in the development of lens opacity is unclear. Table 6 shows the large number with this, increasing with age. Many are presumably coincidental as it is common in the general population, though Brandt et $a l^{18}$ suggest from histology that most cataracts in leprosy are secondary to inflammation. But is there a specific cataract caused just by the presence of mycobacteria in the eye? ffytche has suggested this, ${ }^{9}$ and a biochemical mechanism for it has been proposed. ${ }^{19}$ In Table 7 the odds ratio of 1.7 for $M B$ as against $P B$ patients for lens opacity suggests a specific link with the bacilli, but lower $95 \% \mathrm{CI}$ is unity so it is inconclusive. The presence of iritis is more important (odds ratio 3.0) while age is the most important risk factor. The visual loss can be temporary, being reversible by cataract extraction. Some have recorded good results from this in leprosy patients, ${ }^{20}$ though these were long inactive cases. It is probable that in more recently active cases, still at risk of reactions, the results are less certain but still fair. ${ }^{21}$ As aphakic correction in this programme has been by spectacles, surgery was not performed for early opacity.

\section{OTHER COMPLICATIONS}

Intraocular pressure can be altered in leprosy. It is usually lowered, ${ }^{22}$ but may be raised. ${ }^{23}$ But unless there are other indications its routine measurement is impractical in the field. No pupil block glaucoma was seen, though patients with extensive synechiae would be at risk. The absence of angle closure from atropinisation (this type of glaucoma is rare here) means it is safe for field workers to use atropine freely. The absence of iris pearls seems to be the case in Africa ${ }^{12}$ and anyway they would only be seen in active lepromatous cases. Leprous keratitis was found in one case only (the neglected case in case report 3), who also had the only limbal staphyloma seen, presumably following a limbal leproma. No active lepromas were seen. The scarcity of these features presumably means patients are presenting before the disease is very advanced, and drug resistance is not occurring.

\section{PREVENTION OF BLINDNESS}

The crucial question is whether levels of complications and visual loss have fallen with MDT. It is hoped that with the massive killing power of rifampicin $(99+\%$ killed with the first dose) plus the prevention of resistance by using more than one drug, this should be so. But to prove it is not easy. A controlled trial cannot be done, and as the whole pattern of care has changed with time, historical controls will be misleading and will have had more time to develop complications. So the question can only be answered indirectly. This study finds that most visual loss from leprosy occurred in patients who started treatment before the programme began in 1973. In those who started in the last two decades, we have been able to find only very few who lost vision from leprosy even when complications occurred. The three who did lose vision (five eyes) had exceptional features especially late presentation, and some may still improve as described in case presentations 3-5. So blindness from leprosy is avoidable with present management, even in adverse conditions.

This programme and the patients have faced many difficulties down the years (now greatly improved). So it is encouraging that the overall prognosis for sight is good. The striking success of MDT in eradicating infection is not being marred by residual disability. Since at present one cannot predict who will get problems, the practical message is the need to watch everyone so as to identify complications early and intervene at once. Complications are only blinding if untreated. Each programme needs to work out methods of training their frontline staff to recognise problems, and to plan policies for their treatment. Training manuals are available. ${ }^{24} 25$ In particular it must be decided who may atropinise patients and use topical steroids when iritis has occurred, who may give systemic steroids for recent facial paralysis, and how to protect exposed cornea. These policies must be realistic so they can be used at once by field staff before damage occurs. They must not just say 'refer' when there is no expert nearby. For cataract surgery referral must be available but this is less urgent. As patients may remain at risk of complications after ending chemotherapy, they must continue to have easy access to care.

We thank Dr P Byass for carrying out the multiple logistic regression modelling and Dr P Courtright and Dr W Felton Ross for help in preparing the paper. Among many coworkers in Ross for help in preparing the paper. Among many coworkers in Uganda, we thank especially Miss P Gilmer and Mr E Biteyo Blindenmission helped finance the field work. 
1 Hansen GA, Bull OB. The leprous disease of the eye. Christiana A Cammermeyer, 1873 (quoted Lancet 1990 335: 578)

2 ffytche TJ. The continuing challenge of ocular leprosy. Br f Ophthalmol 1991; 75: 123-4.

3 Courtright PD. Defining the magnitude of ocular complications from leprosy: problems of methodology. Int $\mathcal{f}$ Lepr 1988; 56: 566-73.

4 WHO Expert Committee on Leprosy, Sixth Report. Geneva: WHO, 1988.

5 Vettom L, Pritze S. Reliability of skin smear results: experiences with quality control of skin smears in different routine services in leprosy control programs. Lepr Rev 1989; 60: 187-96

6 Ridley DS, Jopling WH. Classification of leprosy according to immunity. Int $\mathcal{F}$ Lepr 1966; 34: 255-73.

7 Courtright P, Johnson GJ. Prevention of blindness of leprosy. Revised ed. London: International Centre for Eye Health, 1991.

8 Mehra V, Minassian DC. A rapid method of grading cataract in epidemiological studies and eye surveys. Br f Ophthalmol 1988; 72: 801-3.

9 ffytche TJ. Residual sight-threatening lesions in leprosy patients completing multidrug therapy and sulphone monotherapy. Lepr Rev 1991; 62: 35-43.

10 Lamba PA, Santoshkumar D, Arthanariswaran R. Ocular leprosy - a new perspective. Leprosy in India 1983; 55: 490-4.

11 Ticho U, Ben Sira I. Ocular leprosy in Malawi. Br $\mathcal{F}$ Ophthalmol 1970; 54: 107-12.

12 Emiru VP. Ocular leprosy in Uganda. Br $f$ Ophthalmol 1970 ; 54: 740-3.

13 Shorey P, Krishnan MM, Dhawan S, Garg BR. Ocular changes in reactions in leprosy. Lepr Rev 1989; 60: changes
14 ffytche TJ. Role of iris changes as a cause of blindness in lepromatous leprosy. $B r f \mathcal{f}$ Ophthalmol 1981; 65:

15 Espiritu CG, Gelber R, Ostler HB. Chronic anterior uveitis in leprosy: an insidious cause of blindness. $\mathrm{Br} \mathcal{F} \mathrm{Oph}$ thalmol 1991; 75: 273-5.

16 Hogeweg M, Kiran KU, Suneetha S. The significance of facial patches and type 1 reaction for the development of facial nerve damage in leprosy. Lepr Rev 1991; 62: 143-9.

17 Karacorlu MA, Cakiner T, Saylan T. Corneal sensitivity and correlations between decreased sensitivity and and correlations between decreased sensitivity and anterior segment pathology

18 Brandt F, Kampik A, Malla OK, Pokharel RP, Wos J. Blindness from cataract formation in leprosy. De Ophthalmol 1983; 7: 1-12.

19 Prabhakaran K. Cataract in leprosy: a biochemica approach. Lepr Rev 1971; 42: 11-3.

20 ffytche TJ. Cataract surgery in the management of late complications of lepromatous leprosy in South Korea. Br $¥$ Ophthalmol 1981; 65: 243-8.

21 Suryawanshi N, Richard J. Cataract surgery in leprosy patients. Int $\mathcal{F}$ Lepr 1988; 56: 238-42.

22 Lewallen $S$, Courtright $P$, Ho-Sung Lee. Ocular autonomic dysfunction and intraocular pressure in leprosy. $\mathrm{Br} f$ Ophthalmol 1989; 73: 946-9.

23 Walton RC, Ball SF, Joffrion VC. Glaucoma in Hansen' disease. Br f Ophthalmol 1991; 75: 270-2.

24 Courtright P, Lewallen S. Guide to ocular leprosy for health workers. Singapore (Talmilep): World Scientific Publishing, 1993.

25 Brand M. Care of the eye in Hansen's disease. 3rd ed. Carville, LA 70721, USA: Gillis W Long Hansen's Disease Centre (Talmilep), 1993. 